\title{
Esclerosis múltiple en una mujer fallecida por quemaduras en el incendio del domicilio.
}

\author{
Multiple sclerosis in a woman died by burns in a \\ house fire.
}

J. Lucena y cols.

Cuad Med Forense 2004; 38:59-65

Mujer de 47 años en situación de invalidez por una esclerosis múltiple de 17 años de evolución. Mientras se encontraba sola en su domcilio se produce un incendio que se inicia en el brasero de la mesa camilla. Debido a su enfermedad neurológica, no puede escapar del foco del incendio y muere como consecuencia de las quemaduras por llama. En la autopsia se ponen de manifiesto quemaduras de tercer grado profundo como consecuencia de la llama que determinan una carbonización parcial del cadáver afectando fundamentalmente a los planos corporales anteriores. Negro de humo en vías respiratorias indicativo de haber respirado en el foco del incendio. No obstante, la carboxihemoglobina encontrada fue de $10,74 \%$, una concentración considerada como leve. En el estudio anatomopatológico, el encéfalo estaba disminuido de tamaño y peso ( I l 40 g) con signos de atrofia cerebral global y dilatación de ventrículos laterales. En los cortes coronales practicados se observaron numerosas placas situadas en la sustancia blanca cerebral (distribución periventricular y subcortical) así como en cerebelo, tronco y médula. En los cortes del

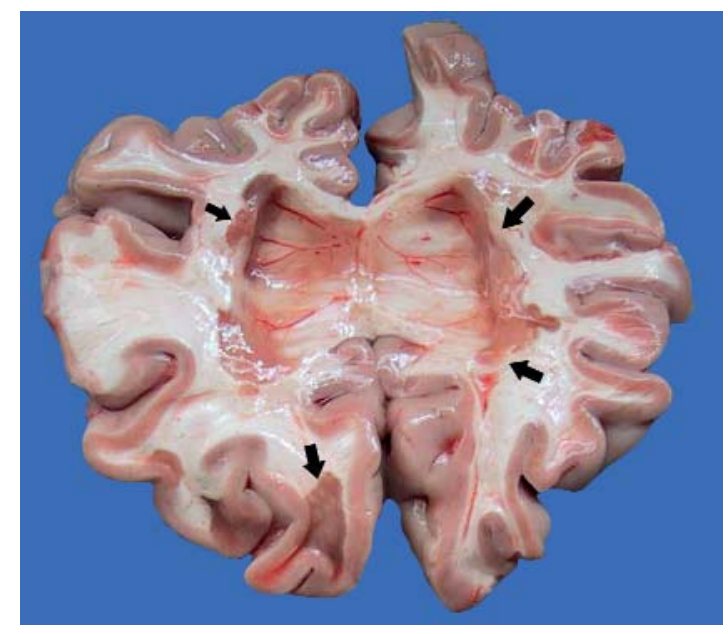

Figura 1.- Corte coronal del cerebro en fresco en el que se aprecia una placa de esclerosis de distribución periventricular y otra subcortical (flechas). Obsérvese la atrofia cerebral con ensanchamiento de surcos y la dilatación de los ventrículos laterales. encéfalo en fresco las placas tenían un aspecto deprimido de bordes bien definidos y un color rosa-pardo (Fig. I). En los cortes practicados tras fijación las placas estaban más endurecidas y eran de color grisáceo (Fig. 2). El estudio histopatológico mediante tinción de mielina (Klüver-Barrera) puso de manifiesto que las placas observadas microscópicamente correspondían a áreas de desmielinización en la sustancia blanca cerebral así como en cerebelo, tronco y médula (Fig. 3). Se observaba un ligero infiltrado inflamatorio de distribución perivascular situado en el margen externo de las lesiones (Fig. 4). 


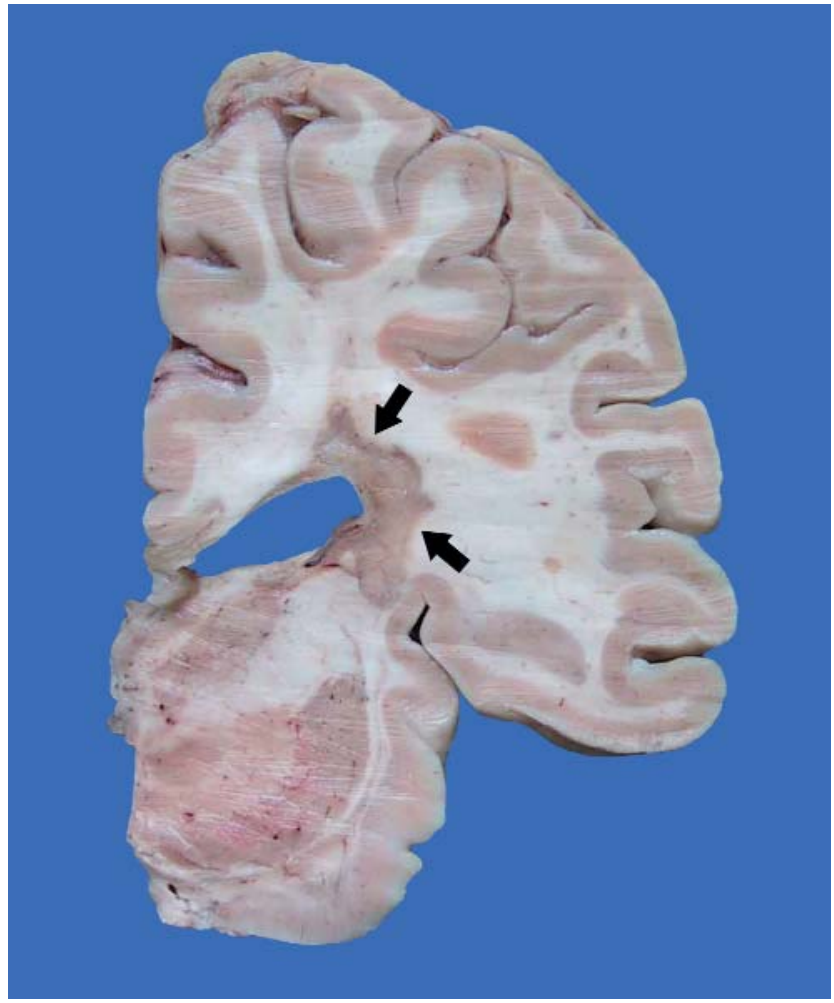

Figura 2.- Corte coronal del cerebro tras fijación en el que se aprecia una placa de esclerosis periventricular (flechas).

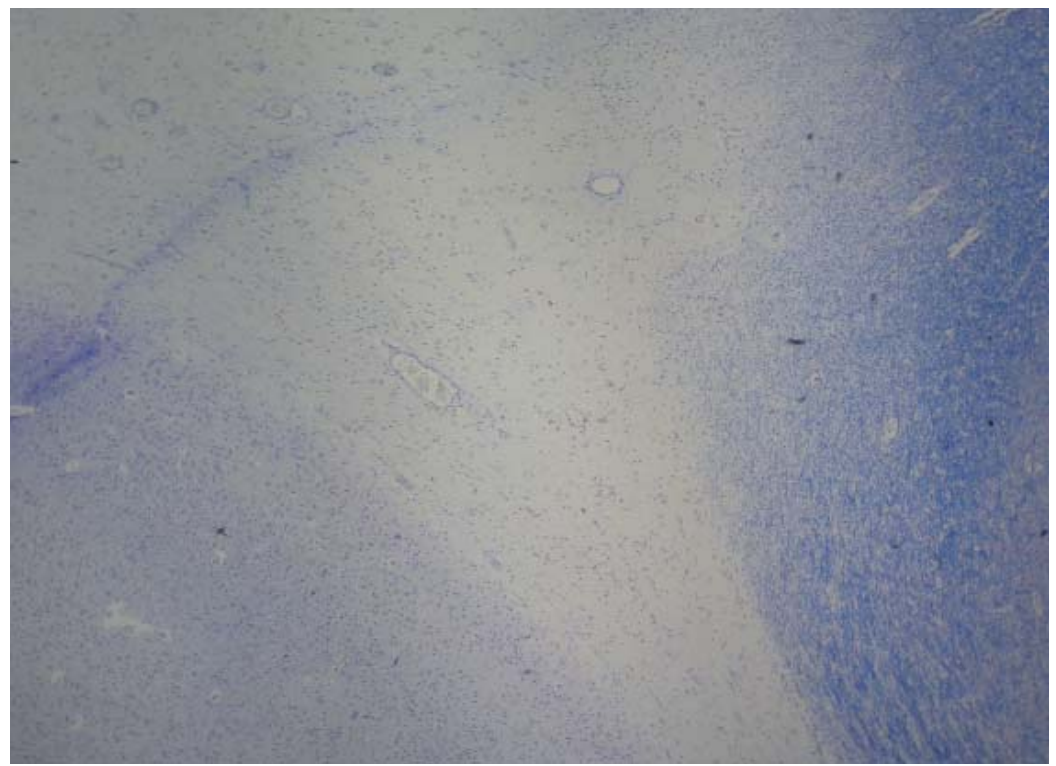

Figura 3.- Estudio histopatológico que pone de manifiesto placa de desmielinización en sustancia blanca subcortical (Klüver-Barrera) 


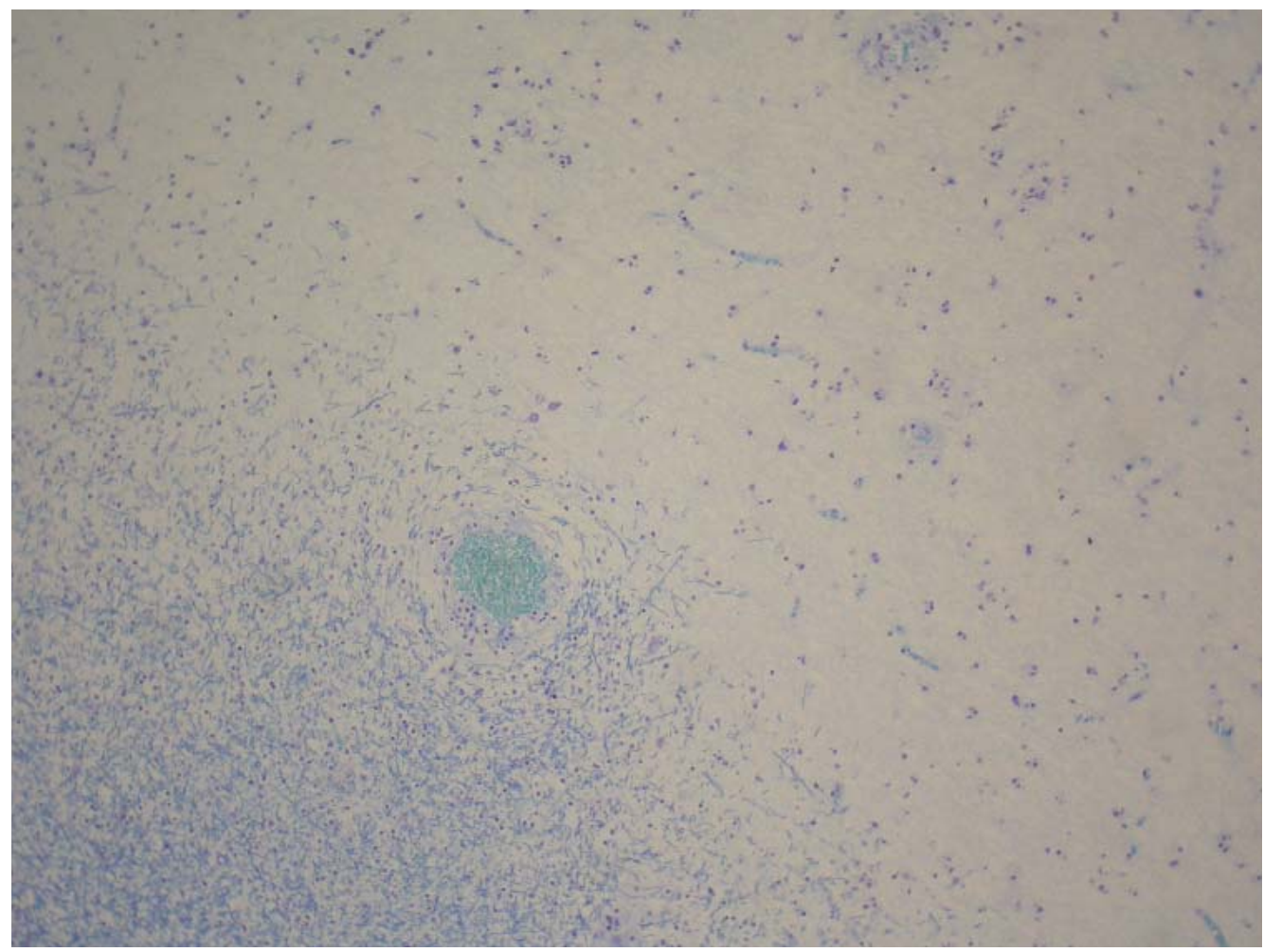

Figura 4.- Zona de transición entre la sustancia blanca normal y una placa desmielinizada (Klüver-Barrera). 